\title{
RARE CASES OF GYNECOLOGICAL CANCERS IN YOUNG GIRLS AND ITS SOCIAL IMPACT: A CASE SERIES
}

\section{Dr. Āshwini Patle}

Dr. Kriti Sahu*
Postgraduate, Dr. B.A. M. Central Railway hospital, Mumbai

Postgraduate, Dr. B.A. M. Central Railway hospital , Mumbai ${ }^{*}$ Corresponding Author

\section{Dr. Anuradha Konda}

\author{
ACHD, Dr. B.A. M. Central Railway hospital , Mumbai
}

\section{ABSTRACT}

Gynecological cancers occur usually in older age women and occurrence in young girls is rare. These girls undergo various types of treatments and the survivors are prone for adverse impacts on their social well being. The current study aims to understand the disease pattern and treatments of these rare cancers and its social impact. 4 cases of young girls with gynecological cancers attending our hospital were studied and social impact of the disease was noted in terms of educational attainment, employment, financial burden, peer and family relationship, marriage etc.

\section{KEYWORDS :} \begin{abstract}
)
INTRODUCTION:

Genital Cancers include cancer of cervix, endometrium, ovary, vagina, vulva, uterine sarcoma etc. These represents a significant proportion of malignancies affecting women. Among these ovarian cancer ranks third in incidence, after cancer cervix and uterine. ${ }^{1}$ There is a wide range of geographical variation in the incidence, distribution and lifetime risk of major genital malignancies. Ovarian cancers constitute around $15-20 \%$ of all genital malignancies. Most common age of presentation is in postmenopausal age. The mean age of diagnosis is $50-79$ years. $^{2}$ Epithelial ovarian cancer constitutes 90 percent of the ovarian cancer and occurs in old age group, while the rest 10 percent includes dysgerminoma, immature teratoma, yolk sac tumours etc. that are seen in age group less than 20 years. Many researches have pointed out that younger age ovarian cancer is associated with improved outcome. ${ }^{2}$
\end{abstract}

Similarly in uterine cancers, most common is cancer endometrium occurring in perimenopausal age group but uterine sarcomas are rare and affect younger age group. ${ }^{3}$ Overall occurence of genital malignancy is very rare in young unmarried females.

Adolescence is a period of great change, and getting cancer diagnosed at this age affects the individual in every single aspect. With improved survival, these cancers in young females and their treatment leads to high level of distress, depression, anxiety, loss of self esteem and body image. They experience difficulty in educational attainment and later in employment and financial stability. They also get problems with maintenance and development of peer and family relationships. Usual emphasis is on the newer modalities of treatment and better survival rates but the aspect of social well being and quality of life is neglected. These patients form a separate group whose lives are no longer normal. The goal of this case series is to give a better knowledge of these rare cancers of young girls and provide better understanding of the life of these survivors.

\section{DETAILS OF CASES:}

Case 1

13 year old girl, presented in the year 2009 with pain abdomen and distention. On examination lump was palpated per abdomen. Ascitic fluid tapping and Mesenteric lymphnode biopsy was suggestive of metastatic poorly differentiated Adenocarcinoma. CAl 25 was raised $(232 \mathrm{U} / \mathrm{mL})$. She received 9 cycles of chemotherapy with paclitaxel and carboplatin.

On follow up in the year 2011 , CT showed multiple cystic lesion in peritoneal cavity, largest $6.5 \times 3.8 \mathrm{~cm}$, left lung bronchiectasis. Received 2 cycle chemotherapy with Ifosfamide , Etoposide, Carboplatin. Exploratory laparotomy with left salpingo-oophrectomy with omentectomy done on $17 / 03 / 2011$. HPR - most likely teratoma with some mucinous cyst ,no malignant component. Was then on follow up for 8 years, asymptomatic.

Follow up in year 2019 showed increased AFP(156 ng/mL). CT scan showed large heterogenous right adnexal cyst $10.7 \times 8.6 \times 8.3 \mathrm{~cm}$ ? malignancy. Biopsy from cyst showed necrotic tumor with few atypical cells. Exploratory laparotomy with excision of pouch of douglas mass and deposits done on $27 / 01 / 2020$. HPR showed yolk sac elements, some signs of carcinoma seen likely clear cell carcinoma.

Post surgery 3 cycles of Ifosfamide, Etoposide, Cisplatin given Is on follow up now.

Social impact: patient is educated till 12th std, missed one year of school in between, could not complete education, unemployed and dependent on family income, unmarried, has one sister, is accompanied by mother and father during her treatment and spend around 2 -3 years in treatment.

\section{Case 2}

13 year old girl, known case of muscular dystrophy, presented in the year 2018 with pain in abdomen. On examination $6 \times 6$ $\mathrm{cm}$ mobile mass palpated in right iliac fossa. USG abdomen showed $5.1 \times 7.2 \mathrm{~cm}$ right adnexal mass. Tumor markers like AFP, beta HCG was normal. CT scan abdomen +pelvis showed well defined heterogenous lesion in right lower abdomen with internal fat density component and foci of chunky calcification ,features suggestive of right ovarian teratoma.

On follow up after one month, amongst all tumor marker LDH and CAl25 were raised (LDH-344 U/L, CAl25 -82.8U/mL). Exploratory laparotomy with left adnexectomy done on 21/8/2018. HPR-left adnexa-mature cystic teratoma, negative for malignancy.

Social impact: patient is educated till 10th std, missed one year of school, is pursuing further education from National Institute Of Open School (wheel chair bound due to muscular dystrophy), has two sisters and spend around 6 months in treatment.

Case 3

19 year old girl, presented in the year 2018 with severe pain in 
left lower abdomen and vomiting. USG showed large cystic lesion $10 \times 5.3 \mathrm{~cm}$ with multiple fine septation, hemorrhagic ovarian cyst with torsion with mild collection in POD in lower abdomen. CA 125 raised (69.4U/mL). In view of spontaneous rupture of left ovarian cyst emergency laparotomy with left salpingo-opherectomy done. HPR- yolk sac tumor of left ovary, peritoneal fluid negative for malignancy.

2 months post surgery she had pain in lower abdomen, vomiting, fever. On examination $8 \mathrm{~cm}$ mass palpable per abdomen. USG abdomen showed liver, anterior abdominal wall and intraperitoneal lesion present showing sign of metastasis. Mild free fluid in morrisons pouch and right iliac fossa. CT scan showed multiple large conglomerate nodular soft tissue lesion in lower abdomen and pelvis $11.9 \times 8.1 \times 8.2$ $\mathrm{cm}$. Loss of fat plane with adjacent loops of bowel and mass effect on bladder. Tumor marker raised (AFP-37077ng/mL, CA $125-327 \mathrm{U} / \mathrm{mL}$, beta HCG-63mIU/mL). She received 4 cycles of bleomycin, etoposide and cisplatin.

Post chemotherapy CT scan showed minimal persistent residual disease. Tumor marker reduced (AFP-9.57ng/mL). Patient is on follow up now

Social impact: patient is pursuing Bachelor of arts (lst year) now, missed 2 years of school, unemployed and dependent on family income, unmarried, is the only child, accompanied by mother, father and cousin brother during her treatment and spent around 2 years in treatment.

\section{Case 4}

16 year old girl presented in the year 2017 with polymenorrhoea and menorrhagia since menarche. H/o pain in lower abdomen. USG Pelvis showed uterus $8.7 \times 3.7 \mathrm{~cm}$, ET$16.3 \mathrm{~cm}$ and $3 \times 2.7 \mathrm{~cm}$ mass in cervical canal protruding through external os. On biopsy of this mass HPR- benign warty growth. Presented in the year 2018 with complaints of pain in lower abdomen, loss of appetite, nausea. USG abdomen showed uterus bulky with $2.5 \times 3.6 \times 4 \mathrm{~cm}$ solid mass in endometrial cavity with moderate vascularity. On Biopsy from endometrial polypoidal mass ,HPR-spindle cell sarcoma with focal rhabdoid morphology .On IHC positive for desmin, myogen, Cyclin Dl suggests embryonal rhabdomyosarcoma. MRI showed single polypoid mass in the uterus with breach at fundus and body posterior aspect involving myometrium with moderate enhancement and bilateral adnexal solid cystic mass. All tumour markers are normal except CA125 raised $(58.78 \mathrm{U} / \mathrm{mL})$. FDG PETCT showed mass in endometrial cavity with Multiple large abdominopelvic confluent solid-cystic lobulated mass occupying majority of the peritoneal cavity with peripheral enhancement and increased FDG uptake.Bilateral mild hydroureteronephrosis. Single $5 \mathrm{~mm}$ nodule in the right lung middle lobe. Treated by IRS IV Induction protocol. Chemotherapy given and CT done showed significant decrease in cystic/necrotic abdominopelvic mass.

16 \# chemotherapy received with Vincristine, actinomycin D and cyclophosphamide.Total abdominal hysterectomy + Pelvic mass removal + pelvic peritonectomy + omentectomy + bilateral ovarian transposition done. HPR-signs of viable rhabdomyosarcoma in the pelvic mass, uterus , rectosigmoid deposit.

Post surgery 23\# external beam radiotherapy to the pelvic cavity and adjuvant chemotherapy given with Vincristine, actinomycin D and cyclophosphamide given. Is on follow up now.

Social impact- patient is educated till $10^{\text {th }}$ std, now took admission in $11^{\text {th }}$ std, missed one year of school in between, has 3 sister and 1 brother, is accompanied by mother and father during her treatment and spend around 1-2 years in treatment.
DISCUSSION:

In this case series we studied 4 different cases of malignancies in girls of adolescent age group. The mean age of presentation was 15 years and all of them presented with abdominal pain, which was evaluated with various investigations and malignancy was detected. All of them had to undergo surgery as a part of treatment which involved removal of their ovaries, tubes, uterus etc. jeopardising their reproductive function and their fertility. As more patients survive cancer, attention is drawn towards the effect of treatments like surgery, chemotherapy and radiation on fertility. ${ }^{5}$ An emerging field of onco-fertility is trying to take care of such issues. Methods like ovarian transposition during surgery, cryopreservation of oocyte or embryo are being used to preserve ovarian function as it was done in one of our patients. Further recurrence of the cancer and requirement of treatment and follow up life long has to be dealt.

Chemotherapy causes side effects like alopecia, weakness , cachexia etc. hampering their body image. Childrens face difficulties in coping with the stresses of surgery, chemotherapy, radiation therapy. ${ }^{6}$ Psychosocial effects include depression, anxiety and concerns about mortality. Special concern to mental health of these survivor is provided by support groups. Research has shown that these patients are comfortable with in-person and web based information support. $^{8}$

Social issues include problems of unattainment of desired education, career goal, finding a life partner and raising a family. Diagnosis of cancer derails all these future plans. Our patients too faced these problems. Most of them missed 1-2 years of schooling. They are unemployed and dependent on family income. Patients feel "left behind" in their career and job trajectories. ${ }^{9}$ Young patients with cancer report feeling isolated and missing out on important normal social activities like school dances, sports due to treatment, hence their general well-being is lost.

Impact on their families is also significant. Families bear financial burden due to the disease and treatment. A study of Medical Expenditure Panel Survey showed substantial health and economic burden on young cancer survivors. ${ }^{10}$ In addition parents give less attention and importance to the other siblings. In our patients also siblings and families were affected due to the disease.

\section{REFRENCES:}

1. Bray F, Ferlay J, Soeriomataram I, Siegel RL, Torre LA, Jemal A. Global cancer statistics 2018: GLOBOCAN estimates of incidence and mortality worldwide for 36 cancers in 185 countries. CA: a cancer journal for clinicians. 2018 Nov;68(6):394-424.

2. Arora N, Talhouk A, McAlpine JN, Law MR, Hanley GE. Long-term mortality among women with epithelial ovarian cancer: a population-based study in British Columbia, Canada. BMC cancer. 2018 Dec 1;18(1):1039.

3. Leung F, Terzibachian JJ, Aouar Z, Govyadovskiy A, Lassabe C. Sarcomes utérins: aspects cliniques et histopathologiques. A propos de 15 cas [Uterine sarcomas: clinical and histopathological aspects. Report on 15 cases]. Gynecol Obstet Fertil. 2008;36(6):628-635. doi:10.1016/ j.gyobfe. 2008. 03. 0126363

4. Warner EL, Kent EE, Trevino KM, Parsons HM, Zebrack BJ, Kirchhoff AC. Social well-being among adolescents and young adults with cancer: a systematic review. Cancer. 2016 Apr 1;122(7):1029-37.

5. Kim, C. H., \& Jeon, G. H. (2012). Fertility preservation in female cancer patients. International Scholarly Research Notices, 2012.

6. McCaffrey, C. N. (2006). Major stressors and their effects on the well-being of children with cancer. Journal of pediatric nursing, 21(1), 59-66.

7. Enskör, K., \& von Essen, L. (2008). Physical problems and psychosocial function in children with cancer. Nursing Children and Young People, 20(3).

8. Love, B., \& Donovan, E. E. (2014). Online friends, offline loved ones, and fulltime media: young adult "mass personal" use of communication resources for informational and emotional support. Journal of Cancer Education, 29(2), 241-246.

9. Grinyer, A. (2007). The biographical impact of teenage and adolescent cancer. Chronic illness, 3(4), 265-277.

10. Guy Jr, G. P., Ekwueme, D. U., Yabroff, K. R., Dowling, E. C., Li, C., Rodriguez, J. L., ... \& Virgo, K. S. (2013). Economic burden of cancer survivorship among adults in the United States. Journal of Clinical Oncology, 31(30), 3749. 